\title{
Elimination of Hazardous Fluoride from Drinking Water using Th-Mn Nanoadsorbent
}

Vaishali Tomar ${ }^{1 *}$ and Dinesh $\operatorname{Kumar}^{2 *}$

${ }^{1}$ Formulation,ABH Nature Product, 11717, New York,USA

${ }^{2}$ School of Chemical Sciences, Central University of Gujarat, Gandhinagar,INDIA

*Corresponding Author: Vaishali Tomar, Formulation,ABH Nature Product, 11717, New York,USA. Email: vaishali.aura08@ gmail.com

Citation: Vaishali Tomar (2017). Elimination of hazardous fluoride from drinking water using Th-Mn nanoadsorbent. Int J Nano Med \& Eng. 2:7, 131-140.

Copyright: :C 2017 Vaishali Tomar. This is an open-access article distributed under the terms of the Creative Commons Attribution License, which permits unrestricted use, distribution, and reproduction in any medium, provided the original author and source are credited.

Received June 14, 2017 Accepted June 23, 2017, Published August 10, 2017

\section{Abstract}

Herein, we have developed Th-Mn nanoadsorbent for the removal of fluoride from aqueous systems. The adsorbent presented high surface area $\left(156.864 \mathrm{~m}^{2} / \mathrm{g}\right)$ and small pore size $(13.3 \AA)$ demonstrating the high porosity of the nanoadsorbent. The adsorbent surface morphology has been characterized by XRD, TEM, BET, and Raman techniques. The fluoride adsorption mechanism was confirmed by FTIR studies. The fluoride uptake conditions were optimized using batch studies. The batch results demonstrated maximum adsorption efficiency $(85 \%)$ at $\mathrm{pH} 6$ within $85 \mathrm{~min}$. The adsorption isotherms were well fitted by the Freundlich isotherm model $\left(\mathrm{R}^{2}>0.870\right)$. The nanoadsorbent presented excellent regeneratability (up to 95\%) with an alkali solution. The property of regeneration and reusability makes it a smart sustainable material for fluoride removal.

\section{Graphical Abstract}

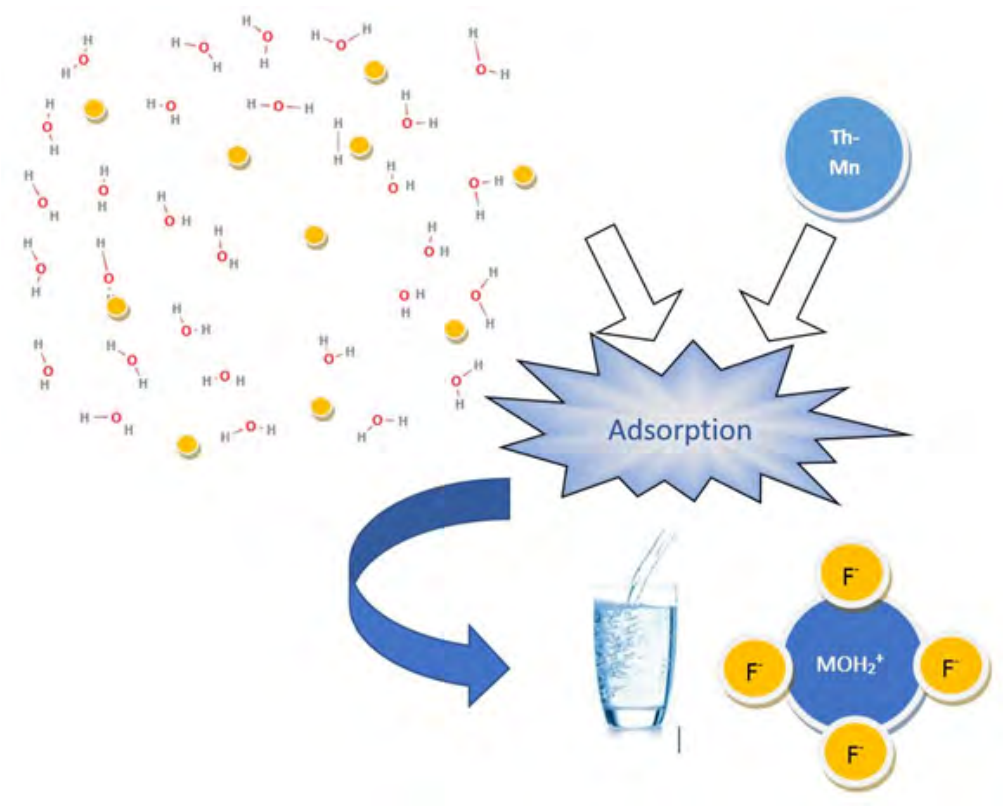

Keywords: Fluoride, adsorption, nanoadsorbent, efficiency 


\section{Introduction}

Fluorine is the most reactive element in the periodic table. Its high reactivity makes it less abundant in elemental form. It is commonly found as inorganic fluorides (including the free anion $\mathrm{F}^{-}$) or as organic fluoride compounds (e.g., freons) ${ }^{1}$. Weathering of fluorides minerals is considered as the main natural source of inorganic fluorides in water. Volcanoes are also a major natural source in increasing atmospheric fluoride concentration through the release of gases such as hydrogen fluoride ${ }^{2-3}$. Inorganic fluorides commonly remain in water as fluorides in acidic $\mathrm{pH}$, low hardness and in the presence of ion-exchange materials ${ }^{4-8}$. Aquatic organisms in soft water are more affected by fluoride pollution as compared to organisms in hard or seawaters due to reduced bioavailability of fluoride ions on increasing water hardness 9 . Unpolluted fresh waters have lower fluoride concentrations $(0.01-$ $0.3 \mathrm{mg} / \mathrm{L})$ as compared to unpolluted seawaters $(1.2-1.5 \mathrm{mg} / \mathrm{L})^{10-}$ 12 .

The low fluoride concentration in drinking water is beneficial for human health, while high fluoride intake can cause severe irreversible dental or skeletal fluorosis. Moreover, it has been known to negatively affect the functioning of kidneys, nerves and muscles $^{13}$. Therefore, the prevention of fluorosis is imperative. Precipitation and adsorption are known since times to bring back excessive fluoride content of water to the permissible limit. Adsorption is the most suitable, moderately simple, efficient and inexpensive method for fluoride removal, particularly in small communities. Several conventional and non-conventional adsorbents like activated alumina ${ }^{14}, \mathrm{Fe} / \mathrm{Al}$ mixed hydroxides ${ }^{15}$, ion exchange resin ${ }^{16}$, solid industrial wastes like red $\operatorname{mud}^{17-18}$, and fly ash ${ }^{19-20}$ were studied for their fluoride adsorption capacities. Still, most of the adsorbent available for fluoride removal are high-priced and technically non-feasible in rural areas. There is a need to develop easily available adsorbents for fluoride removal which are safe and easy use at small community level. Herein, we have developed a Th-Mn nanoadsorbent by means of simple precipitation process followed by heat treatment to employ it for the efficient fluoride removal from aqueous systems ${ }^{20-23}$.

\section{Materials and methods}

\section{Materials}

All reagents like $\mathrm{NaF}, \mathrm{NaOH}, \mathrm{HCl}$ were of analytical reagent grade. The two metal salts like $\mathrm{Th}\left(\mathrm{NO}_{3}\right)_{2} \cdot \mathrm{xH}_{2} \mathrm{O}$ and $\mathrm{MnSO}_{4} \cdot \mathrm{H}_{2} \mathrm{O}$ were purchased from E. Merck Ltd. India and utilized without further purification. The standard fluoride stock solution (1000 $\mathrm{mg} / \mathrm{L}$ ) was prepared and different concentrations fluoride solutions for experimental studies were obtained by appropriate dilution ${ }^{24-27}$.

\section{Adsorbent preparation}

Both metal salt solutions were prepared by dissolving $5.02 \mathrm{~g}$ of $\mathrm{Th}\left(\mathrm{NO}_{3}\right)_{4} \cdot \mathrm{xH}_{2} \mathrm{O}$ in $100 \mathrm{~mL}$ and $3.02 \mathrm{~g}$ of $\mathrm{MnSO}_{4} \cdot \mathrm{H}_{2} \mathrm{O}$ in $100 \mathrm{~mL}$. They were mixed and $\mathrm{pH}$ was adjusted to 7.4-7.8 by drop wise addition of $2 \mathrm{M} \mathrm{NaOH}$ solution under vigorous stirring, leading to precipitation. The obtained precipitate was filtered and washed many times with distilled deionized water. Further, the precipitate was calcined in a muffle furnace with slow increase of temperature from 80 to $600{ }^{\circ} \mathrm{C}$ for $6 \mathrm{~h}$. Finally, the adsorbent was cooled and then crushed manually into fine powder below 200 meshes $^{28-35}$.

\section{Characterization of adsorbent}

The FTIR spectrum of the adsorbent was recorded on a FTIR spectrophotometer (Agilent 660, USA) using $\mathrm{KBr}$ pellets ${ }^{36-38}$. FTIR spectra of the adsorbent before and after fluoride adsorption were recorded under experimental conditions in the range of 600 $4000 \mathrm{~cm}^{-1}$.

$\mathrm{X}$-ray diffraction (XRD) patterns of adsorbent were obtained using Bruker D8 ADVANCE X-ray diffractometer, Germany with $\mathrm{Cu}$ $\mathrm{K} \alpha$ radiation. The scanning speed was maintained at $0.5 \mathrm{sec} / \mathrm{step}$ in the range of $10-80^{\circ} \mathrm{C}$ with a scan step of $0.02^{\circ} \mathrm{C}$ at $80{ }^{\circ} \mathrm{C}^{39-42}$.

Transmission electron microscopy (TEM) micrographs before and after adsorption were obtained using a Philips CM 200 FEG microscope recorded at $200 \mathrm{KeV}^{43-45}$. Raman spectral analysis was carried out on an Instrument Advantage 532 (Raman). Excitation was achieved using $514.5 \mathrm{~nm}$ line of argon ion laser with an output power ${ }^{46-48}$.

The specific surface area of the nanoadsorbent was determined by Nova 2000e, Quantachrome Instruments Limited, USA by recording nitrogen adsorption isotherms at $77.35 \mathrm{~K}$. The obtained data were processed using Brunauer, Emmett and Teller (BET) method to evaluate specific surface area using BET equation shown below.

$$
1 /\left(\mathrm{W}\left(\left(\mathrm{p} \_\alpha(\mathrm{p})-1\right)\right)\right)=1 /\left(\mathrm{W} \_(\mathrm{m}) \mathrm{C}\right)+(\mathrm{C}-1) /\left(\mathrm{W} \_(\mathrm{m}) \mathrm{C}\right)\left(\mathrm{p} / \mathrm{p} \_\mathrm{o}\right)
$$

A linear plot of $1 /\left[\mathrm{W}\left(\mathrm{p} / \mathrm{p} \_\mathrm{o}\right)-1\right]$ against $\mathrm{p} / \mathrm{p} \_$o gives a straight line where $\mathrm{W}$ is the quantity of the gas adsorbed, $\mathrm{p} / \mathrm{p} \_\mathrm{o}$ is the relative pressure, W_( $\mathrm{m})$ is the quantity of adsorbed monolayer gas and C is the BET constant ${ }^{49-51}$.

\section{Batch adsorption experiments}

Batch adsorption experiments were conducted to study the adsorption isotherms.For that, $1.2 \mathrm{~g}$ adsorbent was added in $50 \mathrm{~mL}$ fluoride solutions of different concentration and with a continuous stirring at $29{ }^{\circ} \mathrm{C}$ with $180 \mathrm{~min}$ of contact time except where the contact time parameter was studied ${ }^{52-54}$. The $\mathrm{pH}$ was adjusted by using $0.1 \mathrm{M} \mathrm{HCl} / \mathrm{NaOH}$ solution. The adsorbent was filtered from the solution after the adsorption experiments and residual fluoride concentration was determined by fluoride meter (Thermo Orion, USA).

\section{Adsorbent optimization}

\section{Effect of $\mathrm{pH}$}

The solution $\mathrm{pH}$ is a key parameter that influences the adsorption phenomena at the solid-water interface. The effect of $\mathrm{pH}$ was studied in the range of solutions having $\mathrm{pH}$ from 1 to 10 with an adsorbent dose of $1.2 \mathrm{~g} / 50 \mathrm{~mL}$, temperature $29^{\circ} \mathrm{C}$ and the contact time of $145 \mathrm{~min}$. The results indicate that fluoride adsorption increases markedly with increasing $\mathrm{pH}$ from 1 to 6 (Fig. 1a). The rate of adsorption increased up to $\mathrm{pH} 6$ due to highly protonated adsorbent surface in acidic medium which gradually increased the attractive forces between positively charged adsorbent surface and negatively charged fluoride ions. The adsorbent demonstrated 
highest efficiency $(\sim 85 \%)$ at $\mathrm{pH} 6$ as a result of ligand exchange interactions between $\mathrm{F}-$ and $\mathrm{OH}-$ groups which is further supported by FTIR studies. Further rise in $\mathrm{pH}$ after 6 caused reduction in the adsorption efficacy as a result of the increased hydroxyl ions concentration which can compete with $\mathrm{F}-$ ions for adsorption active sites. Also, it may be may be a result of development of negative surface charge on adsorbent55.

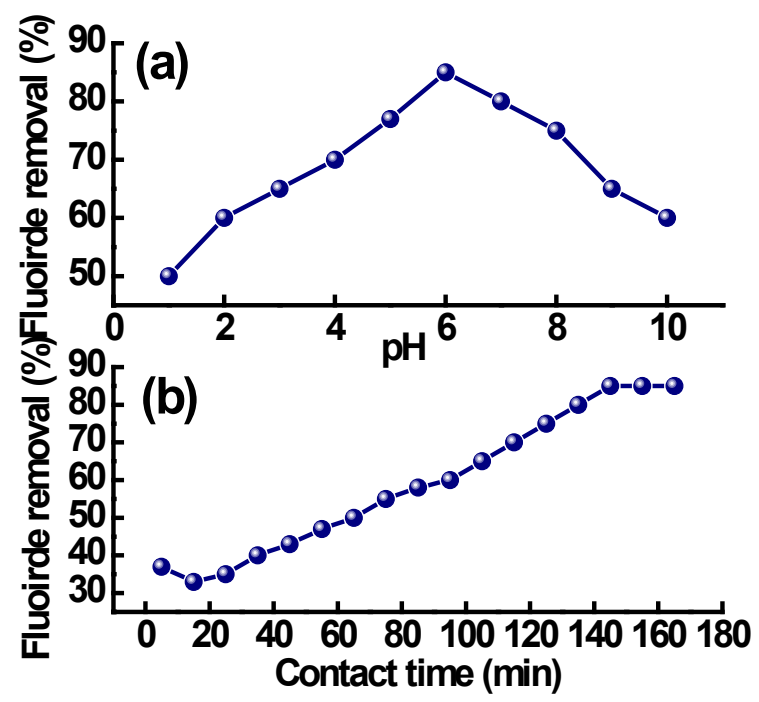

Fig. 1. Influence of the $\mathrm{pH}$ (a) and contact time (b) on fluoride adsorption capacity.

\section{Effect of contact time}

The effect of the contact time on adsorption efficiency was studied at normal room temperature $\left(29^{\circ} \mathrm{C}\right)$ by changing the contact time from 2 to 180 min under similar experimental conditions as described above. Fluoride adsorption (Fig. 1b) was rapid during the first $145 \mathrm{~min}$, where maximum adsorption occurred (85\%). However, the adsorption rate slowed down after 145 min possibly due to the attainment of the equilibrium and later on became almost constant at the later stage of adsorption. Similar results have been reported in the literature ${ }^{56-58}$.

\section{Effect of adsorbent dose}

The effect of adsorbent dose on fluoride adsorption was determined by varying the adsorbent dose from 0.1 to $1.5 \mathrm{~g} / 50 \mathrm{~mL}$. The results demonstrated that the removal percentage increased with increase in adsorbent dosage (Fig. 2a) because of the availability of more number of active sites with dose. Further, increase in adsorbent dose not considerably raises the adsorption rate due to the presence of numerous available adsorbent sites as compared to fluoride ion concentration. Therefore, Th-Mn nanoadsorbent shows maximum fluoride removal efficiency at $1.2 \mathrm{~g} / 50 \mathrm{~mL}^{59-60}$.

\section{Effect of initial fluoride concentration}

The effect of fluoride ion concentration was studied by varying the initial fluoride ion concentration from 10.0 to $45.0 \mathrm{mg} / \mathrm{L}$ under

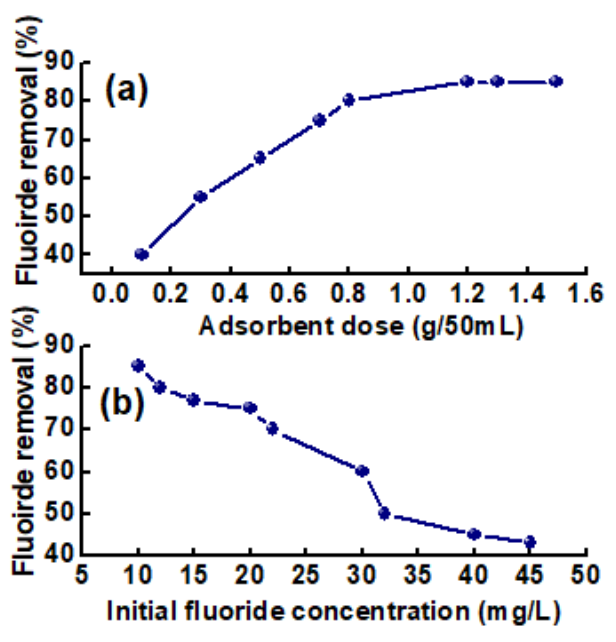

Fig. 2. Influence of the adsorbent dose (a) and initial fluoride concentration (b) on fluoride adsorption capacity.

present experimental conditions (Fig. 2b). The $\mathrm{F}^{-}$adsorption decreased with increase in initial fluoride ion concentration and later on became almost constant at higher fluoride concentrations as a result of availability of fewer adsorption active site then available fluoride ions concentrations. The maximum adsorption capacity $(85 \%)$ was observed at the initial fluoride concentration of $10 \mathrm{mg} / \mathrm{L}^{61-64}$.

\section{Results and discussion}

\section{FTIR studies of adsorbent}

FTIR spectrum of adsorbent before fluoride adsorption shows the transmission band at $3392 \mathrm{~cm}^{-1}$ due to $\mathrm{H}_{2} \mathrm{O}$ stretching and a transmission peak of high intensity at $1634 \mathrm{~cm}^{-1}$ due to bending vibrations of $\mathrm{H}_{2} \mathrm{O}$ (Fig. 3). Further, the FTIR peak at $1050 \mathrm{~cm}^{-1}$ corresponds to metal hydroxyl group (M-OH) bending vibrations (Fig. 3). A slight broadening of $-\mathrm{OH}$ stretching vibration band at $3504 \mathrm{~cm}-1$ after fluoride adsorption corresponds to the formation of O-H-F (Fig. 4). It could be seen that the disappearance of peak at $1050 \mathrm{~cm}^{-1}$ after adsorption demonstrates the hydroxyl group exchange with the fluoride ions ${ }^{65-70}$. The appearance of a new broad band in the region $500-800 \mathrm{~cm}^{-1}$ after fluoride adsorption can be attributed to the complexation of fluoride ions with nanoadsorbent (Fig. 4).

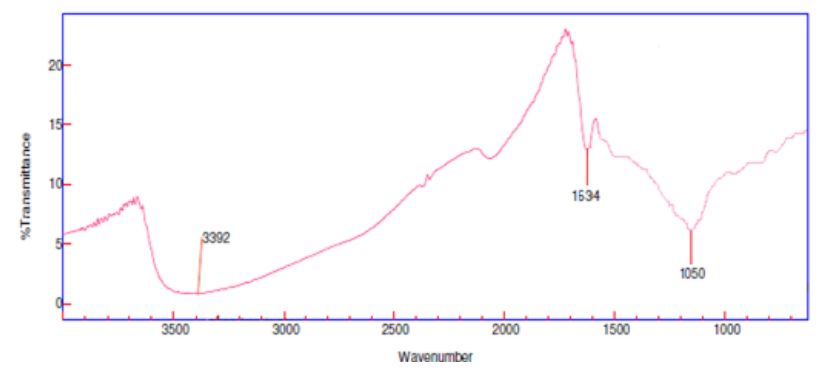

Fig. 3: FTIR spectrum of Th-Mn nanoadsorbent before fluoride adsorption. 


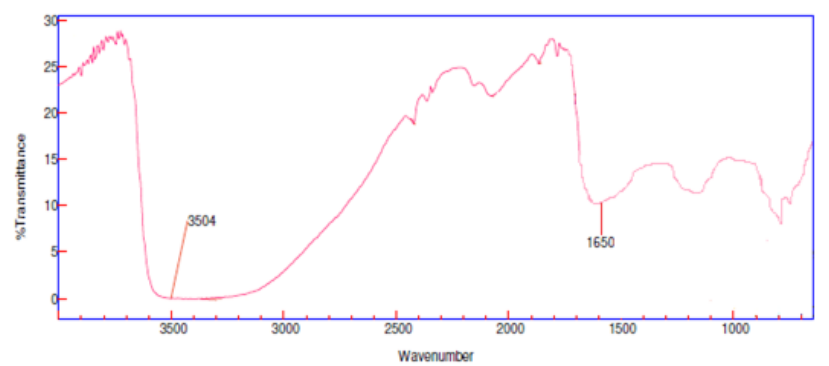

Fig. 4: FTIR spectrum of Th-Mn nanoadsorbent after fluoride adsorption

\section{XRD studies}

The presence of XRD peaks at $2 \theta 17.6^{\circ}, 29.09^{\circ}, 44.2^{\circ}$ supports the presence of $\mathrm{MnO} 2$ species (Fig. 5 (a)). The presence of $\mathrm{ThO}_{2}$ in lesser amount made its phase hard to detect. It could be due to the formation of Th-Mn solid species where Th species entered the lattices of $\mathrm{MnO}_{2}$.

Adsorption of fluoride caused reduction of the peak intensity and depletion was found in peak $19.5^{\circ}$ and $29^{\circ} 71-74$ (Fig. 5 (b))

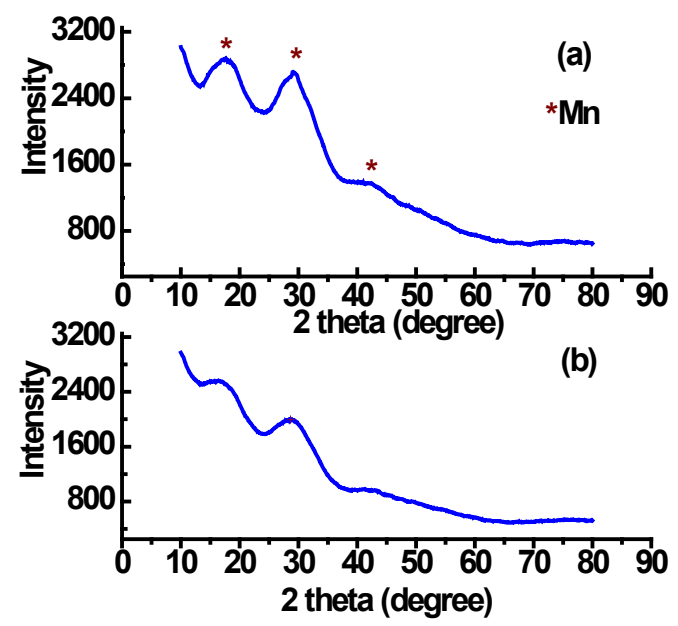

Fig. 5. XRD pattern of Th-Mn nanoadsorbent before (a) and after (b) fluoride adsorption.

\section{TEM analysis}

The TEM image (Fig. 6a) demonstrates agglomerated particles with not well defined shapes ${ }^{75-78}$. The average size of particle increased after fluoride adsorption due to accumulation of fluoride ions on the surface of the nanoadsorbent (Fig. 6b) (Table 1).

Table 1

Average particle size of nanoadsorbent before and after fluoride adsorption

\begin{tabular}{|c|c|c|}
\hline Adsorbent & \multicolumn{2}{|c|}{ Average Particle size (nm) } \\
\hline & Before fluoride adsorption & After fluoride adsorption \\
\hline Th-Mn nanomaterial & 15.3 & 26.6 \\
\hline
\end{tabular}
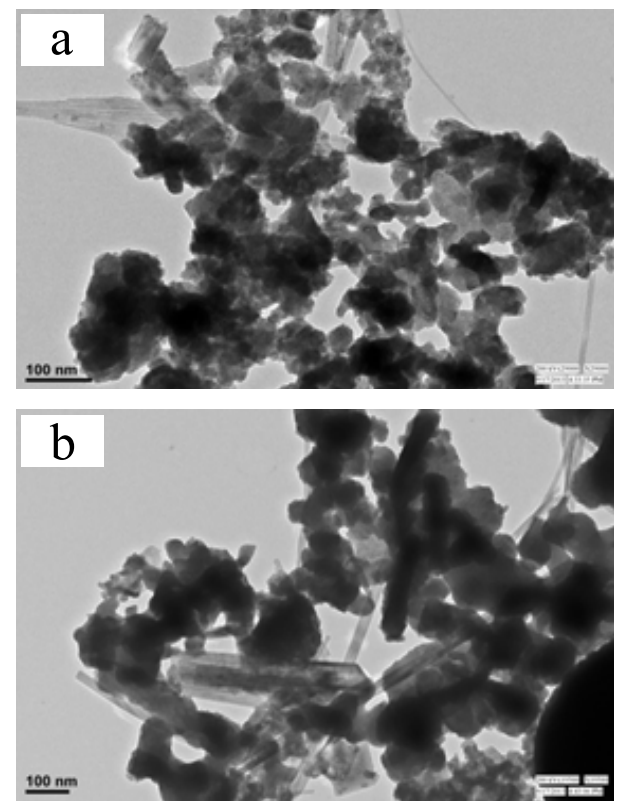

Fig. 6. TEM images of nanoadsorbent before (a) and after (b) fluoride adsorption.

\section{Raman spectroscopy}

The involvement of ion exchange between $\mathrm{F}$ - and $\mathrm{OH}$ - ions was further confirmed by the Raman spectra of nanoadsorbent before and after fluoride adsorption (Fig. 7and 8). The peak at $497 \mathrm{~cm}^{-1}$ was attributed to characteristic peak of Th-O vibrations, and the reduced intensity of the present peak after adsorption may be due to fluoride adsorption ${ }^{79-80}$.

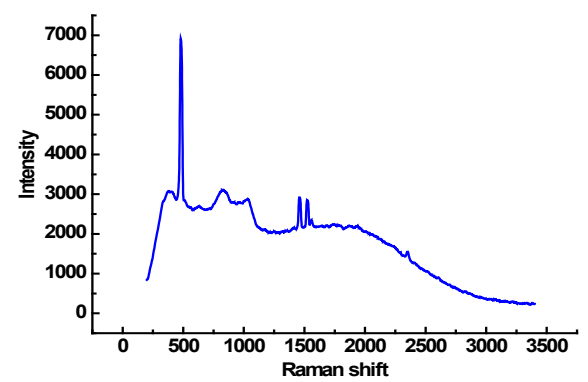

Fig.7. Raman spectrum of Th-Mn nanoadsorbent before fluoride adsorption.

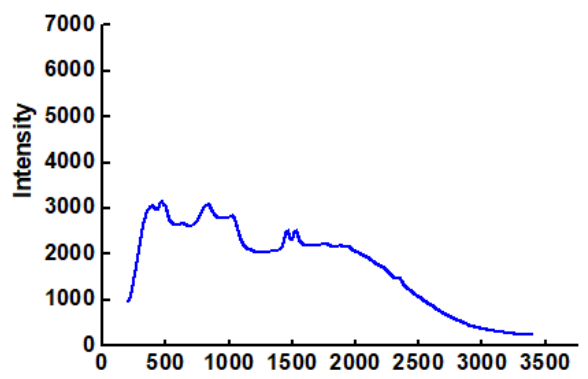

Fig. 8. Raman spectrum of Th-Mn nanoadsorbent after fluoride adsorption. 


\section{BET analysis}

The specific surface area is an imperative characteristic of adsorbents, and BET specific surface area of the nanoadsorbent before and after fluoride adsorption were determined using nitrogen adsorption/desorption at $77 \mathrm{~K}$, Fig. 9. The data is presented in Table 2. The pore size distribution and pore characteristics were analyzed based on Dubinin-Astakhov (D-A) equation, and the plot is shown in Fig. 10. The increase in surface area decreased the pore radius as found in the present study (Table 2). The increase in surface area supports the view that a major structural change occurred during the adsorption of the fluoride ions Table 2. Higher adsorption capacity results in an extensive fluoride adsorption both on the exterior adsorbent surface and inside of the pores. Therefore, the BET surface area of adsorbent is dominated by the surface area of adsorbate. The small size of adsorbate (fluoride) presents high surface area thereby increasing the overall surface area of adsorbent ${ }^{81-83 .}$

Table 2 Surface area and D-A pore size of nanoadsorbent

\begin{tabular}{|c|c|c|c|}
\hline Adsorbent & & Surface area $\left(\mathrm{m}^{2} / \mathrm{g}\right)$ & D-A (Pore Size) $\AA$ \\
\hline \multirow{2}{*}{ Th-Mn nanoadsorbent } & before fluoride adsorption & 156.864 & 13.30 \\
\cline { 2 - 4 } & after fluoride adsorption & 182.582 & 10.40 \\
\hline
\end{tabular}

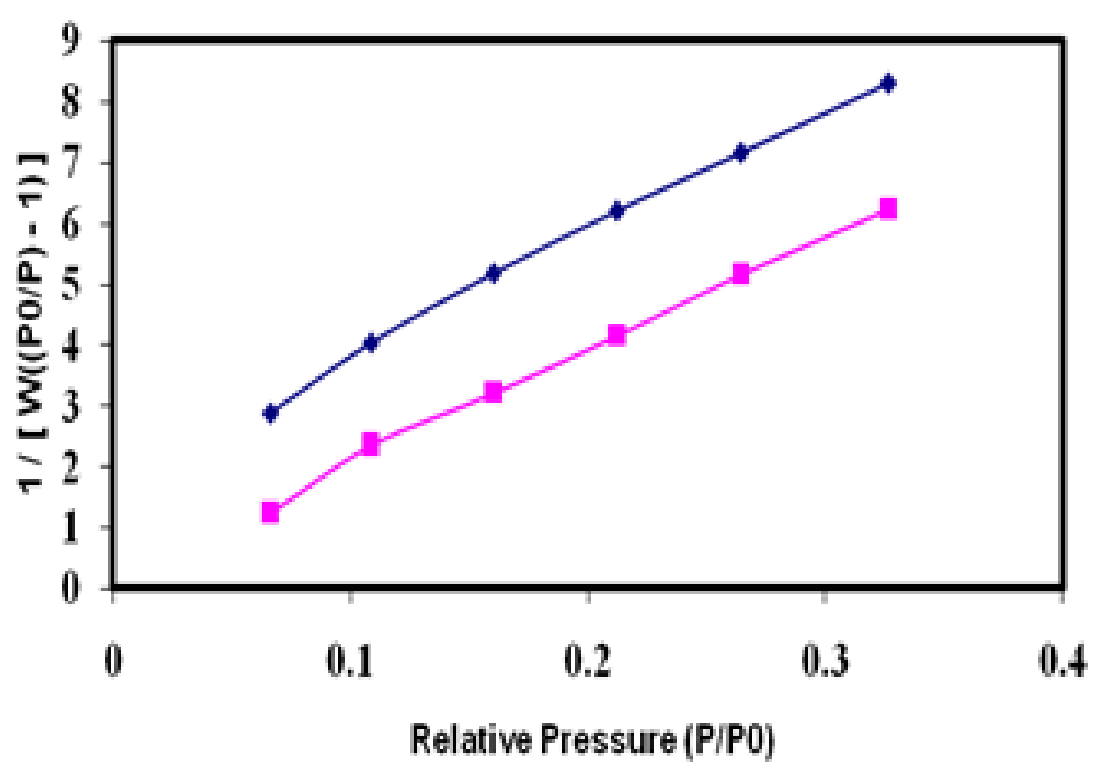

Fig. 9. BET surface area plots where, pink line presents before fluoride adsorption, blue line presents after fluoride adsorption.

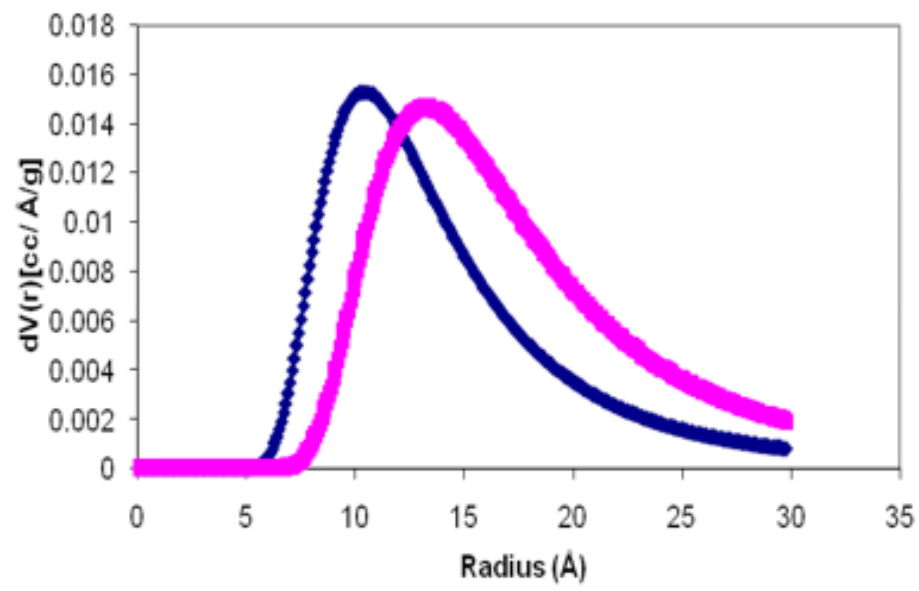

Fig. 10. D-A plots for pore radius where, pink line presents before fluoride adsorption, blue line presents after fluoride adsorption. 


\section{Adsorption isotherm}

Equilibrium adsorption isotherms for fluoride adsorption were determined in batch mode at $\mathrm{pH} 6.0$ and $298 \mathrm{~K}$. The adsorption capacity of nanoadsorrbent was determined by means of following equation84-85:

$\mathrm{Q} \_\mathrm{m}=\left(\mathrm{C}_{\mathrm{o}}-\mathrm{C}_{\mathrm{e}}\right) \mathrm{V} / \mathrm{M}_{\mathrm{s}}$

Where, Qm is the adsorption capicity $(\mathrm{mg} / \mathrm{g})$,

$\mathrm{C}_{\mathrm{o}}$ is the initial fluoride concentration $(\mathrm{mg} / \mathrm{L})$,

$\mathrm{C}_{\mathrm{e}}$ is the equilibrium fluoride concentration $(\mathrm{mg} / \mathrm{L})$,

$\mathrm{V}$ is the volume of solution $(\mathrm{L})$,

Ms is the mass of the adsorbent $(\mathrm{g})$.

The Langmuir and Freundlich isotherm models were employed to analyze the experimental adsorption equilibrium data (Fig. 11 and 12).

\section{Langmuir Isotherm model}

Langmuir model presumes monolayer mode of adsorbate molecules binding on that the surface valence active site of the adsorbent and homogenous adsorption of adsorbate molecules86. The experimental data agreed with the equations of the Langmuir adsorption isotherm as shown below

$\mathrm{Q}_{\mathrm{e}}=\mathrm{Q}_{\mathrm{o}} \mathrm{bC}_{\mathrm{o}} /\left(1+\mathrm{bC}_{(\mathrm{e})}\right)$

$1 / \mathrm{Q}_{\mathrm{e}}=1 / \mathrm{Q}_{\mathrm{o}}+1 / \mathrm{bQ}_{\mathrm{o}} \mathrm{C}_{\mathrm{e}}$

where, Qe is saturation adsorption capacity $(\mathrm{mg} / \mathrm{g})$,

$\mathrm{C}_{\mathrm{e}}$ is the equilibrium concentration of adsorbate in liquid phase $(\mathrm{mg} / \mathrm{L})$,

$\mathrm{Q}_{0}$ and $\mathrm{b}$ are equilibrium constants.

\section{Freuindlich Isotherm model}

In Freundlich adsoprtion isotherm, the curve demonstrates the relation between concentration of contact, this model bencomes invalid at high pressure conditions where as the Langmuir model relates the adsorption of molecules on the adsorbent surface to the concentration of solution at a fixed temprature. The empirical Freundlich isotherm model and its linear form can be expressed as follows:

$\mathrm{Q}_{\mathrm{e}}=\mathrm{K}_{\mathrm{f}} \mathrm{C}_{\mathrm{e}}{ }^{(1 / \mathrm{n})}$

$\log \mathrm{Q}_{\mathrm{e}}=\log \mathrm{K}_{\mathrm{f}}+1 / \mathrm{n} \quad \log \mathrm{C}_{\mathrm{e}}$

where $\mathrm{Kf}$ and $\mathrm{n}$ are constants whose values are calculated by linear fitting of $\log$ Qe vs. $\log \mathrm{Ce}$. All the parameters are calculated and are tabulated in Table 3. Evaluation of the parameters demonstrates that the Freundlich model presents higher correlation coefficients $\mathrm{R}^{2}=0.870$ as compared to that of Langmuir model (Fig. 6 and 7) $\left(\mathrm{R}^{2}=0.82\right)$.

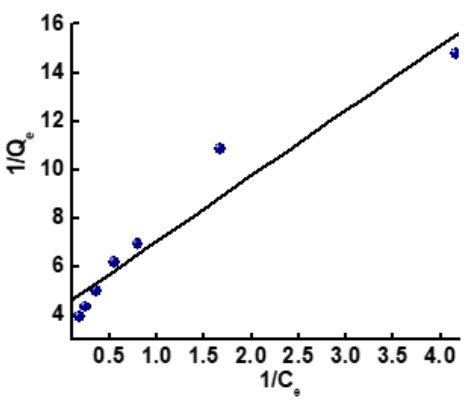

Fig. 11. Linear model of Langmuir isotherm.

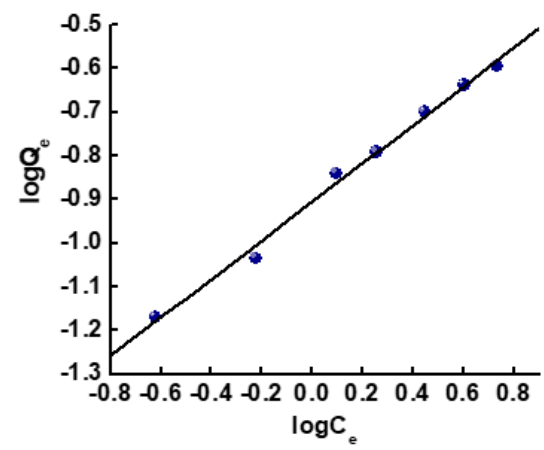

Fig. 12. Linear model of Freundlich isotherm

Table 3 The Langmuir and Freundlich constants

\begin{tabular}{|l|l|l|l|l|l|l|l|}
\hline Adsorbent & \multicolumn{4}{|l|}{ Langmuir Constants } & \multicolumn{4}{l|}{ Freundlich Constant } \\
\hline Th-Mn & $\mathrm{Q}_{0}$ & $1 / \mathrm{b}$ & $\mathrm{R}^{2}$ & $\mathrm{~K}_{\mathrm{f}}$ & $1 / \mathrm{n}$ & $\mathrm{N}$ & $\mathrm{R}^{2}$ \\
\hline & 1.194 & 0.223 & 0.820 & 0.967 & 0.043 & 23.250 & 0.870 \\
\hline
\end{tabular}




\section{Regeneration and Reusability}
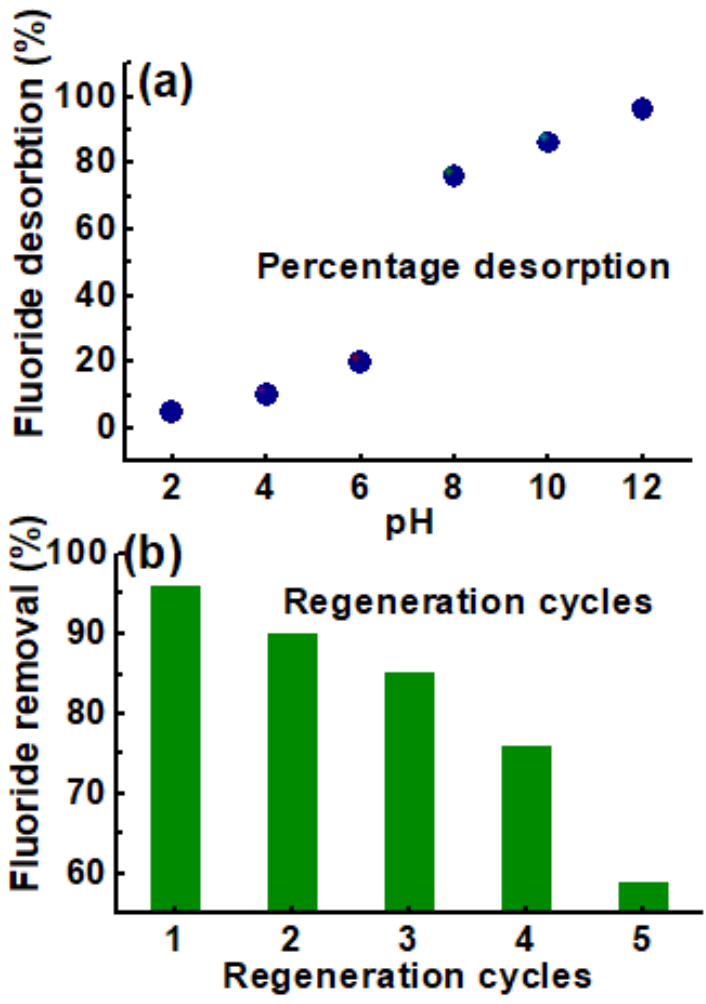

Fig. 13. Fluoride desorption (a) and regeneration (b) studies.

Regeneration and reusability of the nanoadsorbent was checked in several adsorptions and desorption cycles ${ }^{90-97}$. The used nanoadsorbent was regenerated by means of $2 \mathrm{M} \mathrm{HCl}$ and $2 \mathrm{M}$ $\mathrm{NaOH}$. Desorption of nanoadsorbent was moderate in acidic $\mathrm{pH}$, while efficient desorption (96\%) occurred in alkaline $\mathrm{pH}$ (Fig. 13a).

Further, 5 times adsorption-desorption cycles were performed and the adsorbent showed reduced adsorbent capacity in fifth cycle (59\%) (Fig.13b). Therefore, the study revealed efficient regeneration and reusability of the nanoadsorbent up to five cycles with considerable efficiency ${ }^{98-111}$.

\section{Conclusion}

In this study, a novel nanocomposite of Th-Mn developed using a co-precipitation process for efficient fluoride uptake from drinking water. The adsorbent presents efficient fluoride adsorption (85\%) at room temperature with contact time of $85 \mathrm{~min}, \mathrm{pH} 6$, and $1.25 \mathrm{~g}$ adsorbent dose in $10 \mathrm{mg} / \mathrm{L}(50 \mathrm{~mL})$ initial fluoride concentration. The rate of fluoride adsorption increased with contact time and adsorbent dose. The adsorption of fluoride is efficiently followed by Freundlich isotherm. FTIR studies which confirmed the involvement of hydroxyl groups in fluoride adsorption in the form of anion exchange processes and electrostatic interaction. BET analysis demonstrated the high surface area favourable for fluoride adsorption. Adsorption experiments revealed potential of Th-Mn nanoadsorbent for fluoride removal from drinking water.

Acknowledgment

We gratefully acknowledge support from the Ministry of Science and Technology and Department of Science and Technology, Government of India under the scheme of Establishment of Women Technology Park, for providing the necessary financial support to carry out this study vide letter No, F. No SEED/WTP/063/2014.

\section{References}

1. A.V. Jamodei, V.S. Sapkal, V.S. Jamode, J. Ind. Inst. Sci. 2004, 84, 163-171.

2. S.S. Dash, M.K. Sahu, E. Sahu, R.K. Patel, New J. Chem. 2015, 39, 7300-7308.

3. Q. Li, B. Wang, W. Li, C. Wang, Q. Zhou, C. Shuanga, A. Li, J. Chem. Technol. Biotechnol. 2015, 91, 1747-1754.

4. M. Malakoo tian, A. Fatehizadeh, N. Yousefi, M. Ahmadian, M. Moosazadeh,, Desalination, 2011, 277, 244-249.

5. M. Frankowski, Microchem. J. 2012, 101, 80-86.

6. S., Ayoob, A. K. Gupta, P. B. Bhakat, V. T. Bhat, Chern. Eng. J., 2008, 140, 6-14.

7. S. Meenakshi, N. Viswanathan, J. Colloid Interface Sci. 2007, 
$308,438-450$.

8. N. Viswanathan, S. Meenakshi, J. Hazard. Mater., 162 (2009) 920-930.

9. V. Tomar, S. Prasad, D. Kumar, Microchem. J. 2014,112, 97103.

10. U.M. Eduok, S.A. Umoren, A.P. Udoh, Arab. J. Chem. 2012, 5, 325-337.

11. K. Singh, D.H. Lataye, K.L. Wasewara, C.K. Yoo, Desalination, 2013, 51,3233-3247.

12. N. Gandhi, D. Sirisha, S. Asthana, A. Manjusha, Res. J. Chem. Sci. 2012, 2, 32-37.

13. A. Goswami, M.K. Purkait, Chem. Eng. Res. Des. 2012, 90, 2316-2324.

14. R. Lavecchia, F. Medici, L. Piga, G. Rinaldi, A. Zuorro, Chem. Eng. Trans. 2012, 26, 225-230.

15. M.G. Sujana, G. Soma, N. Vasumathi, S. Anans, J. Fluorine Chem. 2009, 130, 749-754.

16. M. Taghi, S. Mohammad, N. Sepehr, M. Zarrabi, S. Mirzaee, R. Saied, A. A. Amrane , Environ. Eng. Manag. J. 2014, 13, 205214.

17. A. Tor, N. Danaoglu, G. Arslan, Y. Cengeloglu, J. Hazard. Mater. 2009,164,271-278.

18. Y. Çengeloğlu, E. Kır, M. Ersöz, Sep. Purif. Technol. 2002, 28, 81-86.

19. C.K. Geethamani, S.T. Ramesh, R. Gandhimathi, P.V. Nidheesh, Desalin. Water Treat. 2014, 52, 19-21.

20. X. Xu, Q. Li, H. Cui, J. Pang, H. An, W. Wang, J. Zhai, Environ. Technol. 2012, 33, 1409-1415.

21. A. Rafique, M.A. Awan, A. Wasti, I.A. Qazi, M. Arshad, J. Chem. 2013, 7.

22. G.E.J. Poinern, M.K. Ghosh, Y.J. Ng, T.B. Issa, S. Anand, P. Singh, J. Hazard. Mater. 2011,185, 29-37.

23. E. Mulugeta, F. Zewge, C.A. Johnson, B.S. Chandravanshi, Desalin. Water Treat.2013, 52,1-8.

24. A. Dhillon, M. Nair, S.K. Bhargava, D. Kumar, J. Colloid Interface Sci. 2015, 457, 289-297.

25. A. Dhillon, D. Kumar, New J. Chem. 2015, 39, 9143-9154.

26. G. Lee, C. Chen, S.T. Yang, W.S. Aha, Micropor. Mesopor. Mater. 2010, 127, 152-156.

27. A. Dhillon, D. Kumar, J. Mater. Chem. A, 2015, 3,4215-4228.

28. S.X. Teng, S.G.Wang, W.X. Gong, X.W. Liu, B.Y. Gao, J. Hazard. Mater. 2009, 168,1004-1011.

29. K. Biswas, S.K. Saha, U.C. Ghosh, Ind. Eng. Chem. Res. 2007,46, 5346-5356.

30. K. Biswas, K. Gupta, A. Goswami, U.C. Ghosh, Desalination., 2010. 255, 44-51.

31. M. Amini, K. Mueller, K. C. Abbaspour, T. Rosenberg, M. Afyuni, K. N. Møller, M. Sarr and C. A. Johnson, Environ. Sci.
Technol., 2008, 42, 3662-3668.

32. B. M. Rahmani, A. H. Mahvi, S. Dobaradaran and S. S. Hosseini, Int. J. Environ. Sci. Tech., 2009, 6, 629-632.

33. S. J. Gaciri and T. C. Davies, J. Hydrol., 1993, 143, 395-412.

34. W. Czarnowski, K. Wrzesniowska and J. Krechniak, Sci. Total Environ., 1996, 191, 177-184.

35. N. Azbar and A. Turkman, Water Sci. Technol., 2000, 42, 403-407.

36. M. Agarwal, K. Rai, R. Shrivastav and S. Dass, J. Cleaner Prod., 2003, 11, 439-444.

37. N. Mameri, A. R. Yeddou, H. Lounici, D. Belhocine, H. Grib and B. Bariou, Water Res., 1998, 32, 1604-1612.

38. Y. Shan and H. Guo, Chem. Eng. J., 2013, 223, 183-191.

39. H. Mjengera and G. Mkongo, Phys. Chem. Earth, 2003, 28, 1097-1104.

40. F. Diaz-Barriga, A. Navarro-Quezada, M. Grijalva, M. Grimaldo, J. P. Loyola-Rodriguez and M. D. Ortiz, Fluoride, 1997, 30, 233-239.

41. E. Kruse and J. Ainchil, Argentina Environ. Geol., 2003, 44, 86-89.

42. I. Abe, S. Iwasaki, T. Tokimoto, N. Kawasaki, T. Nakamura and S. Tanada, J. Colloid Interface Sci., 2004, 275, 35-39.

43. D. Banks, C. Reimann, O. Røyset, H. Skarphagen and O. M. Sæther, Appl. Geochem., 1995, 10, 1-16.

44. A. Goswami and M. K. Purkait, Sep. Sci. Technol., 2011, 46, 1797-1807.

45. W. B. Apambire, D. R. Boyle and F. A. Michel, Environ. Geochem., 1997, 33, 13-24.

46. N. B. Reddy and K. S. S. Prasad, Indian J. Environ. Health, 2003, 45, 285-288.

47. E. J. Reardon and Y. Wang, Environ. Sci. Technol., 2000, 34, 3247-3253.

48. F. Shen, X. Chen, P. Gao and G. Chen, Chem. Eng. Sci., 2003, 58, 987-993.

49. G. de la Puente, J. J. Pis, J. A. Menendez and P. Grange, J. Anal. Appl. Pyrolysis, 1997, 43, 125-138.

50. S. Ayoob and A. K. Gupta, Crit. Rev. Environ. Sci. Technol., 2006, 36, 433-487.

51. M. Mahramanlioglu, I. Kizilcikli and I. O. Bicer, J. Fluorine Chem., 2002, 115, 41-47.

52. N. J. Chinoy, Indian J. Environ. Toxicol., 1991, 1, 17-32.

53. P. T. C. Harrison, J. Fluorine Chem., 2005, 126, 1448-1456.

54. X. Fan, D. J. Parker and M. D. Smith, Water Res., 2003, 37, 4929-4937.

55. Y. Zhou, C. Yu and Y. Shan, Sep. Purif. Technol., 2004, 36, 89-94.

56. M. Islam and R. K. Patel, Chem. Eng. J., 2011, 169, 68-77. 
57. K. Banerjee, G. L. Amy, M. Prevost, S. Nour, M. Jekel, P. M. Gallagher and C. D. Blumenschein, Water Res., 2008, 42, 33713378.

58. Q. Guo and J. Tian, Chem. Eng. J., 2013, 231, 121-131.

59. A. M. Raichur and M. J. Basu, Sep. Purif. Technol., 2001, 24, 121-127.

60. A. Tor, N. Danaoglu, G. Arslan and Y. Cengeloglu, J. Hazard. Mater., 2009, 164, 271-278.

61. A. Tor, Desalination, 2006, 201, 267-276.

62. G. Alagumuthu and M. Rajan, Chem. Eng. J., 2010, 158, 451457.

63. G. Alagumuthu and M. Rajan, Hem. Ind., 2010, 64, 295-304.

64. A. Tor, J. Hazard. Mater., 2007, 141, 814-818.

65. K. M. Popat, P. S. Anand and B. D. Dasare, React. Polym., 1994, 23, 23-32.

66. F. Luo and K. Inoue, Solvent Extr. Ion Exch., 2004, 22, $305-$ 322.

67. I. B. Solangi, S. Memon and M. I. Bhanger, J. Hazard. Mater., 2009, 171, 815-819.

68. S. Meenakshi and N. Viswanathan, J. Colloid Interface Sci., $2007,308,438-450$.

69. N. Viswanathan and S. Meenakshi, J. Hazard. Mater., 2009, 162, 920-930.

70. R. Malaisamy, A. Talla-Nwafo and K. L. Jones, Sep. Purif. Technol., 2011, 77, 367-374.

71. S. Chakrabortty, M. Roy and P. Pal, Desalination, 2013, 313, 115-124.

72. E. Ergun, A. Tor, Y. Cengeloglu and I. Kocak, Sep. Purif. Technol., 2008, 64, 147-153.

73. M. M. Emamjomeh, M. Sivakumar and A. S. Varyani, Desalination, 2011, 275, 102-106.

74. U. T. Una, A. S. Koparal and U. B. Ogutveren, Chem. Eng. J., 2013, 223, 110-115.

75. R. Simons, Desalination, 1993, 89, 325-341.

76. P. Sehn, Desalination, 2008, 223, 73-84.

77. S. K. Adhikary, U. K. Tipnis, W. P. Harkare and K. P. Govindan, Desalination, 1989, 71, 301-312.

78. B. Kemer, D. Ozdes, A. Gundogdu, V. N. Bulut, C. Duran and M. Soylak, J. Hazard. Mater., 2009, 168, 888-894.

79. M. Mohapatra, S. Anand, B. K. Mishra, D. E. Giles and P. Singh, J. Environ. Manage., 2009, 91, 67-77.

80. P. Miretzky and A. F. Cirelli, J. Fluorine Chem., 2011, 132, 231-240.

81. Y. Tian, M. Wu, R. Liu, D. Wang, X. Lin, W. Liu, L. Ma, Y. Li and Y. Huang, J. Hazard. Mater., 2011, 185, 93-100.

82. M. Karthikeyan, K. K. S. Kumar and K. P. Elango, Desalination, 2011, 267, 49-56.
83. A. Bhatnagar, E. Kumar and M. Sillanpää, Chem. Eng. J., 2011, 171, 811-840.

84. J. L. Davila-Rodriguez, V. A. Escobar-Barrios, K. Shirai and J. R. Rangel-Mendez, J. Fluorine Chem., 2009, 130, 718-726.

85. D. Thakre, S. Jagtap, N. Sakhare, N. Labhsetwar, S. Meshram and S. Rayalu, Chem. Eng. J., 2010, 158, 315-324.

86. S. M. Prabhu and S. Meenakshi, Journal of Water Process Engineering, 2014, 2, 96-104.

87. B. Zhao, Y. Zhang, X. Dou, X. Wu and M. Yang, Chem. Eng. J., 2012, 185-186, 211-218.

88. L. Chen, B. Y. He, S. He, T. J. Wang, C. L. Su, and Y. Jin, Powder Technol., 2012, 227, 3-8.

89. J. Kim and B. V. der Bruggen, Environ. Pollut., 2010, 158, 2335-2349.

90. W. X. Gong, J. H. Qu, R. P. Liu and H. C. Lan, Chem. Eng. J., 2012, 189-190, 126-133.

91. L. Borah and N. C. Dey, Indian J. Chem. Technol., 2009, 16, 361-363.

92. G. Moges, F. Zewge and M. Socher, J. African Earth Sci., 1996, 22, 479-482.

93. P. P. Coetzee, L. L. Coetzee, R. Puka and S. Mubenga, Water SA, 2003, 29, 331-338.

94. G. Karthikeyan, A. Pius and G. Alagumuthu, Indian J. Chem. Technol., 2005, 12, 263-272.

95. A. Teutli-Sequeira, V. Martı'nez-Miranda, M. Solache-R1'os and I. Linares-Herna'ndez, J. Fluorine Chem., 2013, 148, 6-13.

96. N. Hamdi and E. Srasra, Desalination, 2007, 206, 238-244.

97. M. Sarkar, A. Banerjee, P. P. Pramanick and A. R. Sarkar, J. Colloid Interface Sci., 2006, 302, 432-441.

98. J. Boken, S. Thatai, P. Khurana, S. Prasad and D. Kumar, Talanta, 2014, 132, 274-284.

99. V. Tomar, S. Prasad and D. Kumar, Microchem. J., 2013, 111, $116-124$

100. S. Thatai, P. Khurana, S. Prasad and D. Kumar, Microchem. J., 2014, 113, 77-82.

101. V. Tomar and D. Kumar, Chem. Cent. J., 2013, 7, 51.

102. M. Kruk and M. Jaroniec, Chem. Mater., 2001, 13, 3169 3183.

103. K. S. W. Sing, D. H. Everett, R. A. W. Haul, L. Moscou, R. A. Pierotti, J. Rouquerol and T. Siemieniewska, Pure Appl. Chem., 1985, 57, 603-619.

104. M. Kruk and M. Jaroniec, Chem. Mater., 2000, 12, 222-230.

105. T. Ahmad, S. Khatoon, S. E. Lofland and G. S. Thakur, Mater. Sci. Semicond. Process., 2014, 17, 207-215.

106. G. E. J. Poinern, M. K. Ghosh, Y. J. Ng, T. B. Issa, S. Anand and P. Singh, J. Hazard. Mater., 2011, 185, 29-37.

107. A. Gil, S. A. Korili and G. Y. Cherkashinin, J. Colloid Interface Sci., 2003, 262, 603-2607. 
108. J. D. Russell, Clay Miner., 1979, 14, 109-114.

109. M. G. Sujana and S. Mohanty, Int. J. Eng. Sci., 2010, 2, 1-12.

110. C. Gao, X. Y. Yu, T. Luo, Y. Jia, B. Sun, J. H. Liu and X. J.
Huang, J. Mater. Chem. A, 2014, 2, 2119-2128.

111. T. F. Lv, W. Ma, G. Xin, R. Wang, J. Xu, D. M. Liu, F. J. Liu and D. C. Pan, J. Hazard. Mater., 2012, 237, 121-132. 